\title{
Health education on multidrug-resistant tuberculosis prevention among tuberculosis patients
}

\author{
Hema Malini $^{1}$, Emil Huriani ${ }^{2}$, Devia Putri Lenggogeni ${ }^{3}$, Shinta Herlina ${ }^{4}$ \\ ${ }^{1,2,3}$ Department of Medical Surgical Nursing, Faculty of Nursing, Universitas Andalas, Indonesia \\ ${ }^{4}$ Undergraduate Program, Faculty of Nursing, Universitas Andalas, Indonesia
}

\section{Article Info}

\section{Article history:}

Received Feb 24, 2020

Revised Nov 20, 2020

Accepted Jan 3, 2021

\section{Keywords:}

Attitude

Health education

Knowledge

Multidrug-resistance

Tuberculosis

\begin{abstract}
The high incidence of multidrug-resistant tuberculosis (MDR-TB) in the community due to the lack of socialization or the provision of health education about MDR-TB. During this time, health education is only focused on tuberculosis (TB) generally. The purpose of this study was to determine the effect of health education on the behavior of MDR-TB prevention in patients with pulmonary tuberculosis in two Community Health Centers in Padang. This study design is quasi-experimental with pre and post-test groups only. The program intervention of health education was conducted for a month with lecture method and group discussion using flipchart and video as media. The sampling technique used purposive sampling were 29 patients with TB who are still in the phase of treatment. Data collection used a set of questionnaires. The data analysis in this study using statistical tests t-test. The results showed, there is a significance influence of health education on knowledge with $\mathrm{p}$-value $=0.000(\mathrm{p} \leq 0.05)$ and attitude with $\mathrm{p}$-value $=0.000$ $(p \leq 0.05)$. The result also showed that $65.5 \%$ of patients taking medication regularly. It was also that there is the effect of health education on the behavior of MDR-TB prevention in TB patients. It is expected that the providing of health education on the prevention of behavior on MDR-TB is emphasized on the motivation and self-efficacy of the patients and involvement of supervision on taking medication.
\end{abstract}

This is an open access article under the CC BY-SA license.

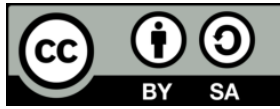

\section{Corresponding Author:}

Hema Malini

Faculty of Nursing

Universitas Andalas

Padang, West Sumatra, Indonesia, 25163

Email: hemamalini@nrs.unand.ac.id; hema.maliniyusuf@gmail.com

\section{INTRODUCTION}

The incidence of Multidrug-Resistant Tuberculosis (MDR-TB) in Indonesia was rated 8 out of 27 countries with the highest burden of MDR-TB in the world. Patients with MDR-TB in Indonesia found as many as 6800 new TB cases with MDR-TB each year, an estimated 2\% derived from new TB cases, and $12 \%$ is obtained from re-treatment TB cases [1]. In the province of West Sumatra, the data show the number of patients BTA (+) was 4,583 people, with a cure rate of $89.36 \%, 10.64 \%$ completed treatment, and the treatment success rate of $69.71 \%$. The discovery of new TB cases with BTA (+) in the city of Padang is 869 people, with a cure rate of $79.63 \% ; 5.75 \%$ level of comprehensive care, a treatment success rate of $85.39 \%$; and death during treatment 34 people per 100,000 population. Based on data half year of 2018, there was total number of new cases for TB with BTA (+) as many as 299 people. In the number of new cases, this may have a higher risk for MDR-TB [2]. 
People with newly diagnosed with TB need to be empowered by the knowledge of how the treatment of their diseases but also to MDR-TB, particularly on the causes of MDR-TB, how the spread of MDR-TB, which can be a risk factor for MDR-TB and MDR-TB prevention. There is several effective strategies that claimed to reduce the MDR-TB infection, such as rapid diagnosis by symptoms screening in high-risk population; effective treatment strategies by supervised the early two weeks of TB medication therapy; and enhanced TB infection control measures; consisting of administrative, engineering or environmental and personal respiratory protection measures [3, 4].

Some elements in the MDR-TB prevention program are improvements in health education and supervision taking medication. Health education is an important to foster patient empowerment and encourage their contribution towards TB control [5, 6]. Providing MDR-TB prevention information through a health education program for people with new diagnosed of TB become essential. the lack of knowledge among community and TB patients might increase the progression of MDR-TB in future [7]. Due to this condition, the patients need to be empowered earlier of this risk for having MDR-TB in the future if they cannot adhere the medication since the beginning of the treatment of TB $[8,9]$. Thus, it is a need to engage health professionals in providing training and education to the patients. In order to improve and knowledge of TB patients, this study proposed to modify the use of media and methods in delivering health education by the health professionals. The purpose of this study was to investigate the effect of health education on prevention behaviors of MDR-TB in patients with pulmonary tuberculosis in Public Health Center, Padang.

\section{RESEARCH METHOD}

This study used a quasi-experimental design with pre-posttest without control group, due to some consideration such as limited number of patients who met the criteria, and also not all the patients were accompanied by the family and willing to involve in this study. We managed to control the confounding factors by limited the program to only new patients that never attended any educational program about TB or MDR-TB.

\subsection{Population and sample}

The sampling technique is a non-probability with purposive sampling method. The population of this study was 61 newly diagnosed with TB BTA (+) in the last three months. Using purposive sampling equation, there were 29 respondents for this study [10]. Respondents were selected by inclusion and exclusion criteria. The inclusion criteria of this study were; TB new case with BTA (+), the participant is still in the phase of treatment (category I and II), patients who failed first-line treatment earlier, patients had good communication and cooperative, and patients who have never received health education about TB generally. While the exclusion criteria in this study were; the patient who had a problem in hearing and vision and patients were absent in.

\subsection{Intervention}

The study was conducted for four months which the health education is given as much as two sessions conducted in one month. Health education activities carried out 45 minutes/session. We involved the health professionals' team in delivering information program to the patients.

In the first session, before health education was given, the respondents were filling out questionnaire knowledge and attitudes about the prevention behavior of MDR-TB (pretest). In this session, respondents were given health education on behavior prevention of MDR-TB in a combination lecture method and discussion. It was also used the electronic media that consists of slide and videos and print media consisting of flipchart and booklets.

After one week, the health education sessions two was conducted in the same topic. In this session, before delivering health education, respondents were evaluated about the prevention behavior of MDR-TB that was explained in the last session. The topic and methods in delivering health education were still the same as the last session.

In the end, the respondents were filling out questionnaires knowledge and attitudes on prevention behavior MDR-TB (post-test). After health education was finished, the respondents were asked to fill form documentation of behavior of taking TB drugs for two weeks. It was an evaluation of performing respondents in taking medication of TB drugs.

\subsection{Data analysis}

The questionnaire of knowledge and attitudes on the prevention behavior of MDR-TB used in the study was derived from the study of the knowledge questionnaire consisted of 15 questions with the scores range from 0-15 using Gutman Scale. For the knowledge, this study assessed the knowledge regarding 
definition of TB and MDR-TB, symptoms, causes, and prevention to MDR TB [8]. Attitude questionnaire consists of 11 questions with Likert scale of 1-4 with an 11-44 score range, which measured the closed attitude of related topics as mention in knowledge [11]. Meanwhile, documentation behavior in taking medication developed by the researcher to be filled out by respondents comprising of day/date/time, type of medication, the rules of taking the medication, taking medication information (taking medication/forget take medication) and the reason for not taking the drugs. The collected data was analyzed using by statistical package for the social science (SPSS) version. The data analysis was performed by the descriptive statistic and paired t-test. The level of significance in the study was set at $\mathrm{p}<0.05$ for statistical analysis.

\subsection{Ethical approval}

This study was approved by Ethics Committee of Faculty of Medicine, Universitas Andalas. All the respondents provided their consents and signed the form prior to their inclusion in this study.

\section{RESULTS AND DISCUSSION}

The result of this study was presented in the description of characteristics and the impact of health education towards knowledge and skill of respondents. Characteristics of respondents showed that of 29 respondents involved in this study were half of them were adults (55.2\%), female (69\%), with the senior high school (69\%) as level of education as shown in Table 1. Similar to this study, a study that conducted among Sahariya Tribes in North India revealed that the characteristics of MDR-TB was at age 45 years which this age is dominant in this study, and female was have higher risk to have MDR-TB [12].

Table 1. Characteristics of respondents in community health centers in Padang

\begin{tabular}{llcc}
\hline \multicolumn{1}{c}{ Characteristics } & \multicolumn{1}{c}{ Criteria } & $\mathrm{f}$ & $\%$ \\
\hline Age & Early adulthood (18-40 years) & 12 & 41.4 \\
& Adults (41-60 years) & 16 & 55.2 \\
\multirow{3}{*}{ Gender } & Elderly $(>60$ years) & 1 & 3.4 \\
\multirow{3}{*}{ Education } & Male & 9 & 31 \\
& Female & 20 & 69 \\
& Elementary & 3 & 10.3 \\
\multirow{3}{*}{ Medication consumption } & Junior high school & 5 & 17.2 \\
& Senior high school & 20 & 69 \\
& Undergraduate & 1 & 3.4 \\
& Adherence & 19 & 65.5 \\
& Non-adherence & 10 & 34.5 \\
\hline
\end{tabular}

Following the two session of health education program for patients with TB, the result showed more than $65.5 \%$ of the respondents have regularity in taking TB drugs, and $34.5 \%$ of respondents are not regular in taking TB drugs. This study revealed that $34.5 \%$ of respondents were irregular in taking OAT is due to long-time consuming OAT. Moreover, the reason why $34.5 \%$ respondents is not regular in taking TB drugs, was respondents forgetting taking TB medication, respondents lack family support, such as late or forget to come to the health services to take medication and receive treatment because nobody accompanies patients to go to the health center. Furthermore, $13.8 \%$ of respondents said the role of the supervisor in taking medication is less active because the family is not reminding them to take medication or supervise the respondent to take medication. A study conducted in Uganda, modify the situation which TB patients keep forgetting taking their medication by applying, a real-time reminder devices and also text messaging, found that patients felt that the technology enable them for following the treatment well [13]. Similar to this study, Lester, et al. [14] recommended that in order to improving support global care for TB patients, the use of mobile phones and SMS as reminder in medication. Thus, in future, in order to enhance the medication adherence among TB patients, health professionals could use the real-time reminder devices and also texting the patients as constant reminder for them.

Furthermore, the regularity of taking TB drugs has shown that health education can influence and improve action in the behaviour prevention MDR-TB on TB patients. Health education should involve the supervisor or family to take medication more effective in promoting taking the medication regularly of TB drugs. A study conducted a systematic review identified there was several structural barriers that can influence the adherence of TB patients taking medication. Barriers such as low motivation, lack of support and also the efforts of health professionals to reach out the patients. It is recommended that using a patientscentred approach play a key role in improving the adherence among TB patients [15]. Moreover, Boru, et al. [16] in their study found there was several factors that contribute to the compliance of medication among TB patients such as: lack of adequate food, poor communication between patients and health professionals, side 
effect of the medications, and also stigma or discrimination [16]. A study also showed that drug-resistance TB was also caused by the condition that TB patients have no access the health services due to patients was traveling outside their hometown, then they failed to report to health professionals [17].

This study has an active involvement from health professionals in delivering the health information about preventing MDR-TB to the newly diagnosis TB patients. The involvement of health professionals as a team would become a significant support for the TB patients. A comparative systematic review about the TB Consolia working a team approach was effective in improving the TB/MDR-TB management in several countries [18]. Garfein and Doshi [19] and Chen, et al. [20] stated that the use of video observed therapy was visible and acceptable for health professional to use as the active support to the TB patients in their medication treatment.

Table 2 presents the impact of health education in TB patients. The effect of health education on prevention behaviour of MDR-TB in community health center in Padang was showed that there are significant influences of health education on knowledge $(\mathrm{p}=0.000)$. Moreover, the table showed there is significant influence on attitudes before and after health education $(\mathrm{p}=0.000)$.

Table 2. The effect of health education on prevention behaviour of MDR-TB in community health centers in Padang

\begin{tabular}{lccccc}
\hline \multicolumn{1}{c}{ Variables } & Mean & SD & Mean Difference & t & p-value \\
\hline Knowledge & 7.90 & 3.619 & 2.83 & 6.37 & 0.000 \\
Pre-test & 10.72 & 2.89 & & & \\
$\begin{array}{l}\text { Post-test } \\
\text { Attitude }\end{array}$ & 26.79 & 5.75 & 4.07 & 6.26 & 0.000 \\
Pre-test & & & & \\
\hline
\end{tabular}

There is significant influence of health education in improving respondents' knowledge. Before following the health education program, it was known only a small proportion of respondents from 29 respondents answered correctly, with the average value of knowledge are 7.90. The analysis items answered correctly are; $48.3 \%$ of respondents aware of MDR-TB treatment for 18-24 months; $48.3 \%$ know how to avoid transmission of $\mathrm{TB}$ to others with closing nose and mouth when coughing or sneezing using a handkerchief, and $44.8 \%$ aware of MDR-TB treatment longer than regular TB. Furthermore, $44.8 \%$ are aware of drug-resistant TB transmission through coughing and droplets of patients; $41.4 \%$ know that TB is not caused by smoking, and 37.9\% know the meaning of MDR-TB. After given health education, there is a significant increase in knowledge; approximately 72.4\% aware of MDR-TB treatment longer than regular TB. In addition, $69.0 \%$ are aware of MDR-TB treatment for 18-24 months, $65.5 \%$ know the meaning of MDR-TB, and $65.5 \%$ know that MDR-TB is not caused by smoking. Furthermore, $62.1 \%$ are aware that MDR-TB is curable. Furthermore, $62.1 \%$ are aware of the transmission of MDR-TB by coughing and droplet of patients. However, only 58.6\% were aware of how to avoid TB to others. The improvement in knowledge especially in the aspect how MDR-TB could be prevented through education program. The engagement program between health professionals and patients was recommended not only in improving knowledge but also in controlling the new cases of TB especially in urban area [6, 21].

Increased knowledge about the prevention of MDR-TB is also influenced by the factor of media used in health education. In this study, the method used was lectures and discussion groups with slide and video. The lecture method is simple in disseminating information quickly. Also, the lecture method is a way to build a relationship with the respondent during health education. The use of electronic media that consists of slides and videos; it is intended that the respondent stay focused so that the material was presented well received. The combination of media (audio-visual) and effective communication during delivering health education program could be effective in improving knowledge and behavior for TB control [4, 22, 23]. AchaAnyi, et al. [24] suggested that in providing health education or health promotion program, the use of social media had important role in providing health information. Even though in this study, the researchers used the WhatsApp group as the reminder for patients to attend the program, the health education was still use face to face interaction. The use of social media could become a recommendation in further study to investigate the impact of social media to the health behaviors.

Besides improving knowledge of respondents, health education has an impact on improving the attitudes on the prevention behavior of MDR-TB. Before given health education, only a small percentage of respondents answered appropriately. It was known $48.2 \%$ disagreed sputum of TB patients to be thrown away carelessly, $41.3 \%$ agreed when taking TB drugs before meals will be useful in killing the TB germs, and $37.9 \%$ disagreed need someone to keep an eye on taking medication. Furthermore, $37.9 \%$ disagreed with TB disease control only the responsibility of health workers alone, and $34.4 \%$ did not agree to discontinue

Int. J. Public Health Sci. Vol. 10, No. 1, March 2021: 27 - 32 
treatment if they are feeling better. In this study, after given health education, a significant increase in the respondents attitudes, about $65.5 \%$ disagreed sputum of TB patients to be thrown away carelessly, $62 \%$ need someone to supervise in taking medication, 58.6\% agreed when taking TB drugs before meals will be useful in killing germs $\mathrm{TB}$, and $58.6 \%$ do not agree about $\mathrm{TB}$ disease control only the responsibility of health workers alone. The changes in the attitude was also shown in the number of TB patients who taking their medication regularly $(64.5 \%)$. Even though there was still number of patients who failed to take medicine regularly. In overcome the non-adherence among TB patients in their medication, it is suggested to use technology such as SMS text as reminders and also to help the patients in managing the complicated treatment (many pills to consume in a day) $[13,23,25,26]$. Furthermore, some approach in involving expert patients to motivate their peers in consuming and strict to their regimen also showed significant impact on the adherence and positive attitudes among TB patients [27]. Similar to this study, health education program intervention was an effective influencing patient's attitude on TB prevention. The improvement in attitudes was showed the provision of health education influence the respondent's attitude. The knowledge of TB is being predictor of both positive attitude and good prevention of TB [28-30].

This study has some limitation regarding the limited number of participants and need to investigate further aspects that influence the adherence. Several studies indicate that nutritional management could and also impact on the adherence, unsatisfactory treatment outcome also revealed as the factor that would lead to MDR TB among patients. It is recommended that in preventing for TB patients becoming MDR-TB in the future, imparting education and awareness, as well as improving the health services among and nutritional management might achieve the treatment among TB patients [17, 31].

\section{CONCLUSION}

Based on the research that has been conducted on the behavior of the prevention of MDR-TB in TB patients in Health Center Padang city by delivering health education, it can be concluded, there is the influence of health education in increasing knowledge of the respondents in preventive health behaviors of MDR-TB. This study used a combination method in delivering the educational sessions such as using audio visual and also providing written information, which was acceptable by the patients. The health education about MDR-TB prevention behaviors can improve the knowledge of pulmonary TB patients. Health education influences respondents' attitudes toward the increase in MDR-TB preventive behavior. Health education about MDR-TB prevention behaviors can improve the attitude of pulmonary TB patients. The result is expected to improve their ability, skills, and experience. As well as broaden its researchers in conducting scientific research, particularly in the provision of health education on prevention behaviors of MDR-TB.

\section{ACKNOWLEDGEMENTS}

The authors are grateful to all the respondents and health professionals involved in this study for their cooperation during data collection and the educational program.

\section{REFERENCES}

[1] Pocket Book of TB MDR Patients. Ministry of Health, RI, 2015.

[2] The Data of TB Patients in Puskesmas Lubuk Begalung. Padang City Health Office, 2018.

[3] G. J. Fox, H. S. Schaaf, A. Mandalakas, E. Chiappini, A. Zumla, and B. J. Marais, "Preventing the spread of multidrug-resistant tuberculosis and protecting contacts of infectious cases," Clinical Microbiology and Infection, vol. 23, no. 3, pp. 147-153, 2017, doi: https://doi.org/10.1016/j.cmi.2016.08.024.

[4] S. Arulchelvan and R. Elangovan, "Effective communication approaches in tuberculosis control: Health workers' perceptions and experiences," Indian Journal of Tuberculosis, vol. 64, no. 4, pp. 318-322, 2017.

[5] G. B. Migliori, et al., "MDR/XDR-TB management of patients and contacts: Challenges facing the new decade. The 2020 clinical update by the Global Tuberculosis Network," International Journal of Infectious Diseases, vol. 92, pp. S15-S25, 2020, doi: https://doi.org/10.1016/j.ijid.2020.01.042.

[6] L. A. Hatzenbuehler, et al., "Increased adolescent knowledge and behavior following a one-time educational intervention about tuberculosis," Patient Education and Counseling, vol. 100, no. 5, pp. 950-956, 2017, doi: https://doi.org/10.1016/j.pec.2016.11.020.

[7] M. Rajendran, R. A. Zaki, and N. Aghamohammadi, "Contributing risk factors towards the prevalence of multidrug-resistant tuberculosis in Malaysia: A systematic review," Tuberculosis, vol. 122, p. 101925, 2020, doi: https://doi.org/10.1016/j.tube.2020.101925.

[8] J. Maharaj, A. Ross, N. R. Maharaj, and L. Campbell, "Multidrug-resistant tuberculosis in KwaZulu-Natal, South Africa: An overview of patients' reported knowledge and attitudes," African Journal Primary Health Care Farmasi Medicine, vol. 8, pp.e1-6 no. 1, 2016, doi: 10.4102/phcfm.v8i1.1089 
[9] A. Acha-Anyi, P. N. Acha-Anyi, S. A. Asongu, and V. S. Tchamyou, "Social media for health promotion: A visual analysis of TB proof South Africa's Facebook page," Technology in Society, p. 101386, 2020, doi: https://doi.org/10.1016/j.techsoc.2020.101386.

[10] Sugiyono, Statistics for Health Research /Statistika untuk Penelitian Kesehata, Jakarta. Alfabeta, 2015.

[11] Y. Fan, et al., "Development and psychometric testing of the Knowledge, Attitudes and Practices (KAP) questionnaire among student Tuberculosis (TB) patients (STBP-KAPQ) in China," BMC Infectious Diseases, vol. 18, no. 213, pp: 0-3, 2018, doi: https://doi.org/10.1186/s12879-018-3122-9.

[12] R. Prakash, et al., "Status of multidrug resistant tuberculosis (MDR-TB) among the Sahariya tribe of North Central India," Journal of Infection and Public Health, vol. 9, no. 3, pp. 289-297, 2016, doi: https://doi.org/10.1016/j.jiph.2015.10.008.

[13] A. Musiimenta, et al., "Digital monitoring technologies could enhance tuberculosis medication adherence in Uganda: Mixed methods study," Journal of Clinical Tuberculosis and Other Mycobacterial Diseases, vol. 17, p. 100-119, 2019, doi: https://doi.org/10.1016/j.jctube.2019.100119.

[14] R. Lester et al., "Mobile phone short message service for adherence support and care of patients with tuberculosis infection: Evidence and opportunity," Journal of Clinical Tuberculosis and Other Mycobacterial Diseases, vol. 16, p. 100-108, 2019, doi: https://doi.org/10.1016/j.jctube.2019.100108.

[15] S. G. de Vries, et al., "Barriers and facilitators to the uptake of tuberculosis diagnostic and treatment services by hard-to-reach populations in countries of low and medium tuberculosis incidence: a systematic review of qualitative literature," The Lancet Infectious Diseases, vol. 17, no. 5, pp. e128-e143, 2017.

[16] C. Gugssa Boru, T. Shimels, and A. I. Bilal, "Factors contributing to non-adherence with treatment among TB patients in Sodo Woreda, Gurage Zone, Southern Ethiopia: A qualitative study," Journal of Infection and Public Health, vol. 10, no. 5, pp. 527-533, 2017, doi: https://doi.org/10.1016/j.jiph.2016.11.018.

[17] C. Timire, et al., "Prevalence of drug-resistant tuberculosis in Zimbabwe: A health facility-based cross-sectional survey," International Journal of Infectious Diseases, vol. 87, pp. 119-125, 2019.

[18] L. D'Ambrosio, et al., "Team approach to manage difficult-to-treat TB cases: Experiences in Europe and beyond," Pulmonology, vol. 24, no. 2, pp. 132-141, 2018, doi: https://doi.org/10.1016/j.rppnen.2017.10.005.

[19] R. S. Garfein and R. P. Doshi, "Synchronous and asynchronous video observed therapy (VOT) for tuberculosis treatment adherence monitoring and support," Journal of Clinical Tuberculosis and Other Mycobacterial Diseases, vol. 17, p. 190-198, 2019, doi: https://doi.org/10.1016/j.jctube.2019.100098.

[20] S.-H. Chen, et al., "Advantage in privacy protection by using synchronous video observed treatment enhances treatment adherence among patients with latent tuberculosis infection," Journal of Infection and Public Health, vol. 13, no. 9, pp. 1354-1359, 2020, doi: https://doi.org/10.1016/j.jiph.2020.03.013.

[21] V. Shibu, et al., "Tapping private health sector for public health program? Findings of a novel intervention to tackle TB in Mumbai, India," Indian Journal of Tuberculosis, vol. 67, no. 2, pp. 189-201, 2020.

[22] C. Colvin, et al., "Quality of TB services assessment: The unique contribution of patient and provider perspectives in identifying and addressing gaps in the quality of TB services," Journal of Clinical Tuberculosis and Other Mycobacterial Diseases, vol. 17, p. 110-117, 2019, doi: https://doi.org/10.1016/j.jctube.2019.100117.

[23] Bahtiar and A. Y. Nursasi, "Utilization of interactive educational media in improving self efficacy of lung tuberculosis patients: Systematic literature review," Enfermería Clínica, vol. 29, pp. 101-105, 2019, doi: https://doi.org/10.1016/j.enfcli.2019.05.006.

[24] A. Acha-Anyi, P. N. Acha-Anyi, S. A. Asongu, and V. S. Tchamyou, "Social media for health promotion: A visual analysis of "TB proof" South Africa's Facebook page," Technology in Society, vol. 63, p. 101386, 2020, doi: https://doi.org/10.1016/j.techsoc.2020.101386.

[25] L. L. H. Lau, N. Hung, W. Dodd, K. Lim, J. D. Ferma, and D. C. Cole, "Social trust and health seeking behaviours: A longitudinal study of a community-based active tuberculosis case finding program in the Philippines," SSM Population Health, p. 100664, 2020, doi: https://doi.org/10.1016/j.ssmph.2020.100664.

[26] N. Sharma, et al., "Tuberculosis (TB) intervention model targeting mobile population of truckers in Delhi, India," Indian Journal of Tuberculosis, vol. 66, no. 3, pp. 382-387, 2019.

[27] Ernawati, A. Saleh, S. A. Pasinringi, and E. A. Abrar, "The influence of expert patients on the increase of medication adherence among tuberculosis patients," Enfermería Clínica, vol. 30, pp. 276-278, 2020, doi: https://doi.org/10.1016/j.enfcli.2019.07.103.

[28] C. I. Bisallah, et al., "Effectiveness of health education intervention in improving knowledge, attitude, and practices regarding Tuberculosis among HIV patients in General Hospital Minna, Nigeria - A randomized control trial," PLOS One, vol. 13, no. 2, 2018, doi: https://doi.org/10.1371/journal.pone.0192276.

[29] N. Sharma, et al., "A comparison of patient treatment pathways among multidrug-resistant and drug-sensitive TB cases in Delhi, India: a cross-sectional study," Indian Journal of Tuberculosis, vol. 67, no. 4, pp. 502-508 2020.

[30] L. M. Kawamura, "Too little too late: Waiting for TB to come," Indian Journal of Tuberculosis, vol. 65, no. 2, pp. 106-108, 2018, doi: https://doi.org/10.1016/j.ijtb.2018.01.002.

[31] A. K. Janmeja, D. Aggarwal, and R. Dhillon, "Factors predicting treatment success in multi-drug resistant tuberculosis patients treated under programmatic conditions," Indian Journal of Tuberculosis, vol. 65, no. 2, pp. 135-139, 2018, doi: https://doi.org/10.1016/j.ijtb.2017.12.015. 